\title{
Translation and validation of Hyperhidrosis Disease Severity Scale
}

\author{
Andrea Yasbek Monteiro Varella ${ }^{1}$, Juliana Maria Fukuda ${ }^{1 *}$, Marcelo Passos Teivelis $^{1}$, José Ribas Milanez de Campos ${ }^{1,2}$, \\ Paulo Kauffman ${ }^{1,2}$, Gabriel Grizzo Cucato ${ }^{1}$, Pedro Puech-Leão ${ }^{2}$, Nelson Wolosker ${ }^{1,2}$ \\ ${ }^{1}$ Vascular Surgery Department, Hospital Israelita Albert Einstein, São Paulo, SP, Brazil \\ ${ }^{2}$ Vascular Surgery Department, Hospital das Clínicas, Faculdade de Medicina da Universidade de São Paulo, São Paulo, SP, Brazil
}

Study conducted at Hospital Israelita Albert Einstein (HIAE) and at Hospital das Clínicas, Faculdade de Medicina da Universidade de São Paulo (HC-FMUSP), São Paulo, SP, Brazil

Article received: $1 / 15 / 2016$ Accepted for publication: 1/18/2016

*Correspondence: Address: Av. Albert Einstein, 627, bloco A1, $4^{\circ}$ andar, sala 423 São Paulo, SP - Brazil Postal code: 05652-000 ju_mfukuda@yahoo.com

\section{SUMMARY}

Introduction: The evaluation of patients with hyperhidrosis $(\mathrm{HH})$ can be accomplished, among other ways, through questionnaires and scales. The Hyperhidrosis Disease Severity Scale (HDSS) has been used as a simple and quick tool to perform this evaluation. Although HDSS has been well established in several languages, it has not been translated into Portuguese, restricting its specific use for Brazilian patients. The aim of this study was to translate HDSS into Portuguese and validate it in a sample of Brazilian subjects.

Method: 290 Brazilian patients (69\% women, with a mean age of $28.7 \pm 9.6$ years and BMI $22.4 \pm 3.9 \mathrm{~kg} / \mathrm{m}^{2}$ ) diagnosed with $\mathrm{HH}$ were evaluated using HDSS, Quality of Life Questionnaire (QLQ) and Sweating Evolution Questionnaire (SEQ) before and after a five-week oxybutynin treatment. Regarding validation, an association between HDSS results and two other questionnaires was performed. To analyze HDSS sensitivity, evaluation of effects pre- and post-treatment with oxybutynin was conducted. Furthermore, HDSS reproducibility was analyzed in a subsample in which the scale was applied again after 7 days of the first follow-up appointment.

Results: There was statistical correlation between HDSS and QLQ and between HDSS and SEQ before treatment and after 5 weeks. Additionally, HDSS was reproducible and sensitive to clinical changes after the treatment period.

Conclusion: The Portuguese version of HDSS has been validated and shown to be reproducible in a Brazilian sample. Therefore it can be used as a tool to improve medical assistance in patients with $\mathrm{HH}$.

Keywords: hyperhidrosis, scales, questionnaires, translations, validation studies.

\section{INTRODUCTION}

Hyperhidrosis $(\mathrm{HH})$ is a somatic disorder characterized by local excess sweating in specific regions of the body due to hyperfunction of eccrine sweat glands, often related to an emotional distress. ${ }^{1}$

There are several ways to diagnose and predict outcomes of HH. In general, objective measures such as transepidermal water loss measurement are used to estimate the amount of sweat of each suspected site affected by $\mathrm{HH}$. However, this approach is expensive and limited by its daily-based measures, ${ }^{2,3}$ resulting from measurements acquired at a particular time of the day and not allowing the analysis of sweating during longer periods.
Hence, questionnaires and scales have been developed to evaluate $\mathrm{HH} .{ }^{4}$ The main advantages of their use include low cost, simplicity, potential self-filling and large-scale application. ${ }^{5}$ Recently, the Hyperhidrosis Disease Severity Scale (HDSS - International Hyperhidrosis Society®) was developed as a quick method, ${ }^{6}$ since it presents only one question with four options of answers related to the implications to patient's daily routine and the degree of tolerance to the symptoms. The advantage of this scale is that its only question is simple and easy to respond, reducing the number of errors and optimizing medical evaluation. 
Despite its global acceptance, HDSS has not been validated or translated into Portuguese, preventing its use in Brazil. Thus, the aim of this project was to translate and validate the Portuguese version of the HDSS, in order to use it as an important scale in Brazilian patients with $\mathrm{HH}$.

\section{Method}

\section{Sample}

A convenience sample of 290 patients of both genders was recruited to this study. After a clear explanation of all procedures, those who agreed to participate in the research protocol signed a consent form. This study was approved by the Local Research Ethics Committee (Approval number at Plataforma Brasil: CAAE40512414.7.0000.0071). Inclusion criteria comprised individuals at the age of 18 years or older with a clinical diagnosis of palmar, axillary, or any association of these two forms of HH. All the patients included in the study had the palmar or axillary form of $\mathrm{HH}$, or an association of both. Patients with compensatory sweating were excluded.

\section{Study design}

After translation and back-translation, HDSS was applied before and after 5 weeks of treatment with oxybutynin. All patients followed the same protocol. Oxybutynin was taken in progressively higher doses: starting at $2.5 \mathrm{mg}$ once daily, which was increased to twice daily after one week, and $5 \mathrm{mg}$ twice daily at the third week. If necessary and tolerated, for patients weighing more than $40 \mathrm{~kg}$, the total dose was increased to $20 \mathrm{mg} /$ day. For patients weighing less than $40 \mathrm{~kg}$, the total dose was not increased after 3 weeks.

In addition, the Quality of Life Questionnaire (QLQ) and the Sweating Evolution Questionnaire (SEQ) were applied. In order to analyze the reproducibility of the Portuguese version of HDSS, a subsample was recruited and reassessed using HDSS 7 days after the first appointment.

\section{Hyperhidrosis Disease Severity Scale translation}

A native qualified Portuguese-speaking professional, specialized in technical translations and fluent in English, as well as experienced with medical literature, carried out the translation. Following the translation there was a trial phase where the understanding of the Portuguese version of HDSS scale was checked out by an additional sample of 40 patients with HH. They outlined major areas for improvement to make it more coherent and understandable. Later, experts evaluated HDSS to make sure its content included all the necessary elements for satis- factory evaluation of the disease, in the light of Brazilian culture, and included the modifications suggested by the patients. After applicable and convenient changes, the "new" HDSS scale (Portuguese version) was back translated into English by another professional with the same skills, who had no access to the original scale (in English). The "new" HDSS scale (in Portuguese) and its classical version in English were compared, and discrepancies were corrected, preserving semantic and idiomatic equivalences to compose a straightforward scale (Figure 1).

\section{Hyperhidrosis Disease Severity Scale}

HDSS consists of a simple and straightforward question with four available answers (grades 1 through 4) related to patient tolerance of $\mathrm{HH}$ symptoms and the negative implications of body perspiration to their everyday lives. Patients are asked to indicate a HDSS score specifically for each site of $\mathrm{HH}$.

In our study, we evaluated only palmar and axillary symptoms, and patients could indicate different site-specific HDSS scores, according to the impairment of quality of life caused by excessive sweating in each area. Patients answered this scale twice: in the first appointment (before starting treatment, week 0), and in the end of the five-week treatment (week 5). Answer graded as 1 meant no perceptible sweating and lack of interference in everyday life; grade 2 , tolerable sweating with seldom interference in everyday life; grade 3 , little tolerable sweating with frequent interference in everyday life, and grade 4 , intolerable sweating with constant interference in everyday life.

\begin{tabular}{|c|c|}
\hline & $\begin{array}{l}\text { Escala de gravidade da hiperidrose } \\
\qquad \text { O meu suor: }\end{array}$ \\
\hline 1 & $\begin{array}{c}\text { Não é perceptível e } \\
\text { nunca } \\
\text { interfere com minhas atividades do dia a dia }\end{array}$ \\
\hline 2 & $\begin{array}{c}\text { É tolerável, mas } \\
\text { às vezes } \\
\text { interfere com minhas atividades do dia a dia }\end{array}$ \\
\hline 3 & $\begin{array}{c}\text { É pouco tolerável e } \\
\text { frequentemente } \\
\text { interfere com minhas atividades do dia a dia }\end{array}$ \\
\hline 4 & $\begin{array}{c}\text { É intolerável e } \\
\text { sempre } \\
\text { interfere com minhas atividades do dia a dia }\end{array}$ \\
\hline
\end{tabular}

FIGURE 1 Translation of Hyperhidrosis Disease Severity Scale (HDSS) into Portuguese. 
For data purposes, the analysis yielded a delta of improvement on HDSS. For example: Pre-treatment (week 0 ) minus post-treatment (week 5) $=$ delta. Thus, delta $=0$ or 1 was considered no improvement; delta $=2$ was considered slight improvement, and delta $=3$ was considered good improvement. For example, if the patient reported at the first appointment HDSS $=4$ (intolerable sweating with high interference in everyday life) and after 5 weeks reported HDSS $=1$ (not noticeable sweating and lack of interference in routine activities), delta was 3 (good improvement).

\section{Quality of Life Questionnaire}

The QLQ is a 20-question form divided into five domains. Each of these domains or group of actions has five levels of answers based on tables that admit a single response. The sum of all points varies between 20 and 100. Quality of life was rated as: much better (20-35), slightly better (36-51), and no improvement (52-100). ${ }^{7,8}$

\section{Sweating Evolution Questionnaire}

The SEQ is based on a scale from 0 to 10 , in which 0 means no sweating improvement and 10 refers to total resolution of symptoms. It was applied 5 weeks after treatment in the follow-up medical appointment. Patients chose a score from 0 to 10 , according to the degree of symptomatic improvement. Results were classified as: no improvement (0-4), slight improvement (5-7) and great improvement (8-10). ${ }^{9-13}$

\section{Statistical analysis}

To determine an association between the HDSS responses and the other two questionnaires (QLQ and SEQ), chi-square test was used. Kappa coefficient was performed to examine the reproducibility of HDSS scale. Finally, sensitivity to treatment was calculated using the Wilcoxon test. Statistical analysis was performed using SPSS software (v. 17, SPSS Inc. Chicago, IL). P-values lesser than 0.05 were considered statistically significant.

\section{Results}

Patients' demographics are summarized in Table 1. Regarding general characteristics of the sample population, $69 \%$ were female. Patients were young, with an average age of 28.7 years [standard deviation (SD) 9.6; range 1860]. Additionally, mean body mass index (BMI) was 22.4 $\mathrm{kg} / \mathrm{m}^{2}$ (SD 3.9; range 10.6-35.4).

Table 2 shows the association between responses obtained with HDSS and QLQ. There was a significant association between the responses obtained with HDSS and QLQ in the palmar group ( $\mathrm{p}<0.001)$, and $94 \%$ of patients who reported good improvement in HDSS were more likely to report much better results with QLQ. There was no significant correlation between HDSS and QLQ in the axillary group.

Table 3 shows the association between responses obtained with HDSS and SEQ. There was a significant association between the responses obtained with HDSS and SEQ in both axillary $(\mathrm{p}<0.01)$ and palmar groups $(\mathrm{p}<0.01)$. As in SEQ, 92 and 96\% of patients who reported good improvement with HDSS (delta $=3$ ) in the axillary and palmar groups, respectively, showed to be more likely to report great improvement with SEQ (in both regions).

In a subsample of 34 patients, we conducted HDSS test-retest after a seven-day interval for patients with axillary HH. This resulted in a kappa index $=0.65(0.29$ to 0.97 , CI $95 \%$ ), showing moderate levels of agreement. In this group, $94 \%$ of patients reported the same values at the first appointment and after a seven-day follow-up. In addition, we carried out HDSS test-retest in a subsample of 58 patients with palmar $\mathrm{HH}$, with a resulting kappa index of 0.84 (0.61 to $1.00, \mathrm{CI} 95 \%$ ), showing substantial degree of agreement. In this group, $96 \%$ of patients reported the same values at the first appointment and after 7 days.

Finally, to evaluate the degree of change in the HDSS scale, we analyzed the patients' responses in the pre-treatment period and after 5 weeks of oxybutynin intake. Wilcoxon values showed differences in median values of HDSS pre- and post-treatment, and turned out to be significant for both groups, palmar $(\mathrm{z}=-11.1$ and $\mathrm{p}<0.01)$ and axillary $(\mathrm{z}=-8.7$ and $\mathrm{p}<0.01)$, respectively.

\section{Discussion}

The aim of this study was to translate and validate the HDSS for Brazilian patients with HH. Results showed that its Portuguese version has good reliability, reproducibility, and is sensitive to changes after clinical treatment, therefore being useful for management of patients with $\mathrm{HH}$.

Currently, there are several ways to evaluate and predict $\mathrm{HH}$ prognosis. In our institution, patient follow-up is now performed using two independent questionnaires: one assesses the degree of improvement in sweating after treatment, and another evaluates the changes in quality of life before and after treatment. These two have been used in different studies, ${ }^{7,8}$ but we believe that the HDSS adds value to medical assistance since it is objective and simple, providing a good evaluation of degree of sweating in different body parts. Moreover, HDSS can be used by non-specialists, as a referral triage tool for patients with $\mathrm{HH}$. 
To assess the reliability of the Portuguese version of the HDSS, an association was made between its results and those obtained through QLQ and SEQ. By comparing data from HDSS and SEQ, we found significant association between the palmar and axillary groups.

On the other hand, comparing responses obtained with HDSS and QLQ, we verified that there was a significant association only in patients with palmar $\mathrm{HH}$. One possible cause for the absence of association in patients with axillary HH is that QLQ is based on questions related to issues regarding excessive sweating in hands, which

TABLE 1 Demographic characteristics of patients.

\begin{tabular}{lllll} 
& & Palmar & Axillary & Total \\
\hline Gender & Female & $70 \%$ & $68 \%$ & $69 \%$ \\
\hline & Male & $30 \%$ & $32 \%$ & $31 \%$ \\
\hline $\begin{array}{l}\text { Age } \\
\text { (years) }\end{array}$ & Average \pm SD & $26.5 \pm 9.0$ & $31.2 \pm 9.8$ & $28.7 \pm 9.6$ \\
\hline & & & & \\
\hline BMI & Range & $18-59$ & $18-60$ & $18-60$ \\
$\left(\mathbf{k g} / \mathbf{m}^{2}\right)$ & Average $\pm S D$ & $22.4 \pm 3.9$ & $23.8 \pm 3.8$ & $22.4 \pm 3.9$ \\
\hline & & & & \\
\hline
\end{tabular}

SD: standard deviation; BMI: body mass index. affects the evaluation of patients with primary axillary $\mathrm{HH}$. Because SEQ is wider on its assessment with an extensive evaluation of other body parts, a positive association between HDSS and SEQ could be due to this fact.

More than association analyses, a comprehensive investigation to evaluate the degree of change in the HDSS scale pre- and post-oxybutynin treatment was performed. This study showed statistical evidence that both palmar and axillary HH improved in the HDSS, expressing its sensitivity to demonstrate changes in patients' symptoms over time under treatment.

Finally, we conducted in a subsample a test-retest 7 days after the first follow-up. Results showed satisfactory reproducibility rates, with 94 and $96 \%$ of axillary and palmar $\mathrm{HH}$ patients, respectively, reporting the same HDSS values when comparing first and second queries.

Our study has some limitations. This Portuguese version of the HDSS was only applied to patients with palmar or axillary $\mathrm{HH}$ and, therefore, the results cannot be generalized to patients with symptoms in other areas. Moreover, we only analyzed the association between HDSS and subjective methods to evaluate HH. Further studies regarding the correlation between HDSS and objective

TABLE 2 Association between responses from Hyperhidrosis Disease Severity Scale (HDSS) and Quality of Life

Questionnaire for patients with axillary $(\mathrm{N}=115)$ and palmar hyperhidrosis $(\mathrm{N}=175)$.

\begin{tabular}{|c|c|c|c|c|}
\hline \multirow[b]{2}{*}{ HDSS (axillary) } & \multicolumn{4}{|c|}{ Quality of Life Questionnaire } \\
\hline & No improvement & Slightly better & Much better & Total \\
\hline No improvement & $21 \%$ & $45 \%$ & $33 \%$ & $100 \%$ \\
\hline Slight improvement & $7 \%$ & $44 \%$ & $49 \%$ & $100 \%$ \\
\hline Good improvement & $0 \%$ & $50 \%$ & $50 \%$ & $100 \%$ \\
\hline \multicolumn{5}{|l|}{ HDSS (palmar) } \\
\hline No improvement & $22 \%$ & $43 \%$ & $45 \%$ & $100 \%$ \\
\hline Slight improvement & $3 \%$ & $40 \%$ & $57 \%$ & $100 \%$ \\
\hline Good improvement & $0 \%$ & $6 \%$ & $94 \%$ & $100 \%$ \\
\hline
\end{tabular}

TABLE 3 Association between responses from Hyperhidrosis Disease Severity Scale (HDSS) and Sweating Evolution Questionnaire for patients with axillary $(\mathrm{N}=115)$ and palmar hyperhidrosis $(\mathrm{N}=175)$.

\begin{tabular}{|c|c|c|c|c|}
\hline \multicolumn{5}{|c|}{ Sweating Evolution Questionnaire } \\
\hline HDSS (axillary) & No improvement & Slight improvement & Great improvement & Total \\
\hline No improvement & $28 \%$ & $25 \%$ & $47 \%$ & $100 \%$ \\
\hline Slight improvement & $0 \%$ & $11 \%$ & $89 \%$ & $100 \%$ \\
\hline Good improvement & $8 \%$ & $0 \%$ & $92 \%$ & $100 \%$ \\
\hline \multicolumn{5}{|l|}{ HDSS (palmar) } \\
\hline No improvement & $28 \%$ & $25 \%$ & $47 \%$ & $100 \%$ \\
\hline Slight improvement & $0 \%$ & $11 \%$ & $89 \%$ & $100 \%$ \\
\hline Good improvement & $0 \%$ & $6 \%$ & $94 \%$ & $100 \%$ \\
\hline
\end{tabular}


evaluations of $\mathrm{HH}$ (e.g. sudorometer) are required to validate these results.

As can be seen from our results, we believe that the translation and validation process of HDSS into Portuguese was successful. It showed significant statistical correlation with other questionnaires (construct validation), good reproducibility rates and sensitivity to changes after clinical treatment. Thus, we can confidently state that the Portuguese version of the HDSS can be used in clinical practice to evaluate the degree of sweating and patient outcomes, as well as manage the treatment of patients with $\mathrm{HH}$, in both palmar and axillary $\mathrm{HH}$.

\section{Conclusion}

The Portuguese version of the HDSS showed reliability and reproducibility in a Brazilian sample and can be used as healthcare tool in patients with $\mathrm{HH}$.

\section{Resumo}

Tradução e validação da Hyperhidrosis Disease Severity Scale

Objetivo: a avaliação de pacientes com hiperidrose $(\mathrm{HH})$ pode ser realizada, entre outras maneiras, por questionários e escalas. O Hyperhidrosis Disease Severity Scale (HDSS) tem sido utilizado como uma forma simples e rápida. Embora o HDSS seja utilizado em outros idiomas, ainda não foi traduzido para o português, limitando sua utilização em pacientes brasileiros. O objetivo deste estudo foi traduzir o HDSS para o português e validá-lo em uma amostra brasileira.

Método: duzentos e noventa (290) pacientes brasileiros

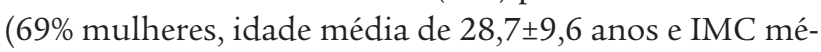
dio de $22,4 \pm 3.9 \mathrm{~kg} / \mathrm{m}^{2}$ ) com $\mathrm{HH}$ foram avaliados pelo HDSS, pelo Questionário de Qualidade de Vida (QQV) e pelo Questionário de Evolução da Sudorese (QES) antes e após 5 semanas de tratamento com oxibutinina. Para a validação de constructo do HDSS, foi realizada a associação entre seus resultados com os dos outros dois questionários. Para analisar a sua sensibilidade, foi realizada a análise do efeito pré e pós-tratamento com oxibutinina. Além disso, foi analisada a sua reprodutibilidade em uma subamostra, na qual a escala foi aplicada novamente após 7 dias da primeira consulta.

Resultados: observamos correlação estatística entre o HDSS e o QQV e entre o HDSS e o QES antes do tratamento e após 5 semanas. O HDSS demonstrou ser reprodutível e sensível em relação ao efeito do tratamento.
Conclusão: a versão em português da escala HDSS apresentou validade e reprodutibilidade em amostra brasileira e pode ser utilizada como instrumento na assistência à saúde de pacientes com $\mathrm{HH}$.

Palavras-chave: hiperidrose, escalas, questionários, traduções, estudos de validação.

\section{References}

1. Vorkamp T, Foo FJ, Khan S, Schmitto JD, Wilson P. Hyperhidrosis: evolving concepts and a comprehensive review. Surgeon. 2010; 8(5):287-92.

2. Ishy A, de Campos JRM, Wolosker N, Kauffman P, Tedde ML, Chiavoni CR, et al. Objective evaluation of patients with palmar hyperhidrosis submitted to two levels of sympathectomy: T3 and T4. Interact Cardiovasc Thorac Surg. 2011; 12(4):545-9

3. Tetteh HA, Groth SS, Kast T, Whitson BA, Radosevich DM, Klopp AC, et al. Primary palmoplantar hyperhidrosis and thoracoscopic sympathectomy: a new objective assessment method. Ann Thorac Surg. 2009; 87(1):267-74; discussion 274-5.

4. Hamm H. Impact of hyperhidrosis on quality of life and its assessment. Dermatol Clin. 2014; 32(4):467-76.

5. Ritti-Dias RM, Gobbo LA, Cucato GG, Wolosker N, Jacob Filho W, Santarém JM, et al. Translation and validation of the Walking Impairment Questionnaire in Brazilian subjects with intermittent claudication. Arq Bras Cardiol. 2009; 92(2):136-49.

6. Solish N, Bertucci V, Dansereau A, Hong HC-H, Lynde C, Lupin M, et al.; Canadian Hyperhidrosis Advisory Committee. A comprehensive approach to the recognition, diagnosis, and severity-based treatment of focal hyperhidrosis: recommendations of the Canadian Hyperhidrosis Advisory Committee. Dermatol Surg. 2007; 33(8):908-23.

7. Amir M, Arish A, Weinstein Y, Pfeffer M, Levy Y. Impairment in quality of life among patients seeking surgery for hyperhidrosis (excessive sweating): preliminary results. Isr J Psychiatry Relat Sci. 2000; 37(1):25-31.

8. de Campos JR, Kauffman P, Werebe EC, Andrade Filho LO, Kusniek S, Wolosker N, et al. Quality of life, before and after thoracic sympathectomy: report on 378 operated patients. Ann Thorac Surg. 2003; 76(3):886-91.

9. Wolosker N, de Campos JR, Kauffman P, de Oliveira LA, Munia MA, Jatene FB. Evaluation of quality of life over time among 453 patients with hyperhidrosis submitted to endoscopic thoracic sympathectomy. J Vasc Surg. 2012; 55(1):154-6.

10. Wolosker N, Teivelis MP, Krutman M, de Paula RP, de Campos JR, Kauffman $\mathrm{P}$, et al. Long-term results of oxybutynin treatment for palmar hyperhidrosis. Clin Auton Res. 2014; 24(6):297-303.

11. Wolosker N, Teivelis MP, Krutman M, de Paula RP, Kauffman P, de Campos JR, et al. Long-term results of the use of oxybutynin for the treatment of axillary hyperhidrosis. Ann Vasc Surg. 2014; 28(5):1106-12.

12. Wolosker N, Teivelis MP, Krutman M, Campbell TPD de A, Kauffman P, de Campos JR, et al. Long-term results of oxybutynin use in treating facial hyperhidrosis. An Bras Dermatol. 2014; 89(6):912-6.

13. Wolosker N, Teivelis MP, Krutman M, de Paula RP, Kauffman P, de Campos $\mathrm{JR}$, et al. Long-term results of the use of oxybutynin for the treatment of plantar hyperhidrosis. Int J Dermatol. 2015; 54(5):605-11. 